\title{
VIOLENCIA POLÍTICA EN SINALOA: EL CASO DE LOS “ENFERMOS” 1972-1978 (LOS LUGARES Y MEDIOS PARA LARADICALIZACIÓN)
}

\author{
Sergio Arturo Sánchez Parra ${ }^{1}$ \\ Universidad Autónoma de Sinaloa-México \\ ssanchez_parra@botmail.com
}

Recepción: 30/05/2008

Evaluación 01/06-15/09/2008

Aceptación: 29/09/2008

Artículo de Reflexión

\section{RESUMEN}

El presente artículo analiza los espacios tales como los Comités de Lucha, Casas del Estudiante Universitario como lugares de sociabilidad estudiantil donde se gestó la radicalidad y legitimación del uso de la violencia como estrategia para la toma del poder en México por parte de un grupo estudiantil de la Universidad Autónoma de Sinaloa denominados como "Enfermos". Asimismo, se estudian las producciones textuales, periódicos, volantes, poesía o las prácticas de lectura que en estos ámbitos de despliegue de dinámicas relacionales se llevaron a cabo como parte de un conjunto de estrategias empleadas para promover una educación política que concientizara a sus miembros en la necesidad de tomar las armas contra el Estado Mexicano, destruirlo e instaurar la dictadura del proletariado. Este proceso de politización adquirido previo a la movilización y el combate armado les dio un cariz especial a los "estudiantes revolucionarios" en la entidad sinaloense, ubicada en el noroeste mexicano entre los años de 1972 a 1978. Se trabaja con la metodología de la historia política y cultural sustentado en fuentes primarias, orales y bibliográficas.

Palabras Claves: Universidad Autónoma de Sinaloa, "Enfermos", Sociabilidad, Casas del Estudiante, Comités de Lucha.

\footnotetext{
${ }^{1}$ Profesor de la Facultad de Historia de la Universidad Autónoma de Sinaloa. Alumno del VIII Semestre del Doctorado en Ciencias Sociales del Centro Universitario de Ciencias Sociales y Humanidades (CUCSH) de la Universidad de Guadalajara. Becario del Consejo Nacional de Ciencia y Tecnología (CONACYT) y del "Programa de Formación de Jóvenes Doctores” que impulsa la institución donde laboró.
} 


\title{
POLITICAL VIOLENCE IN SINALOA: THE CASE OF THE "PATIENTS" 1972-1978 (PLACES AND MEANS FOR THE RADICALIZATION)
}

\author{
Sergio Arturo Sánchez Parra \\ Universidad Autónoma de Sinaloa-México \\ ssanchez_parra@hotmail.com
}

\begin{abstract}
This article explores the spaces such as "Comités de Lucha"(fight committees) and "Casas del Estudiante" (student's houses) as places of sociability, where the radical gesture and legitimization of the use of violence as strategy to take power in Mexico by a student group at the Universidad Autónoma de Sinaloa, called "Los Enfermos" (The sick). It also explores the textual productions. Newspapers, pamphlets, poetry or the practice of reading in these areas of deployment of the dynamic relation were carried out as a part of a set of strategies to promote education policy, to sensitize its members on the need to take up arm against the State of Mexico, and to destroy, if necessary, to set up the dictatorship of the proletariat. This politization process acquired prior to the mobilization and armed combat had a special character: the "revolutionary students" in the Sinaloa entity, located in northwestern Mexico between the years 1972 and 1978. This article is concerned with methodology of the political and cultural history, sustained at primary, oral and bibliographical sources.
\end{abstract}

Key Words: Universidad Autónoma de Sinaloa, Sociability, Casas del Estudiante, Comités de Lucha.

\section{INTRODUCCIÓN}

El trabajo pretende analizar la importancia que tuvieron los espacios donde un segmento de estudiantes universitarios sinaloenses conocidos como "Los Enfermos"2 desplegaron sociabilidades de tipo formal-asociativo, las cuales

\footnotetext{
${ }^{2}$ Dicha denominación fue puesta por las grupos estudiantiles antagónicos a ellos, como los miembros de las Juventudes Comunistas Mexicanas (JCM), organización perteneciente al Partido Comunista Mexicano (PCM) y los integrantes del membrete José María Morelos y Pavón que tuvo amplias simpatías entre alumnos y profesores de la Universidad Autónoma de Sinaloa. El término "Enfermo" utilizado de manera peyorativa por sus detractores, hace alusión a las críticas que en su tiempo hizo el líder de la revolución rusa Lenin al conjunto de jóvenes radicales que en ese momento priorizaban la lucha armada frente al empleo de cualquier otra estrategia para la toma del poder. En el célebre libro, "El izquierdismo: enfermedad infantil del comunismo" plasmó sus críticas a este tipo de conducta como a la vez planteó que dependiendo de la circunstancia política y económica eran las estrategias, las alianzas grupales a utilizar. Por su parte, “Los Enfermos” adoptaron el mote con aires de orgullo. En los pasillos que albergaron en ese entonces la Institución, el Edificio Central arengaban a las “masas universitarias”, ¡SSí, estamos enfermos del virus rojo del comunismo. Y no hay medicina que nos cure!.
} 
contribuyeron a forjar un imaginario socio-político en donde la violencia se convirtió en la estrategia más adecuada para la destrucción del Estado y la instauración de la dictadura del proletaria en Sinaloa y México.

En esos lugares este grupo, gracias a la edición de todo tipo de textualidades, la circulación y distribución de textos con "contenidos radicales", las prácticas de lecturas, individuales o grupales, fue posible la construcción de un proyecto político radical que se difundió empleando una infinidad de recursos en el espacio público local, L metodología empleada giro en torno a la historia política y se sustentó en fuentes primarias.

\section{Un poco de historia}

Entre la primavera de 1972 hasta 1978, los "Enfermos", grupo estudiantil radical pertenecientes a la Federación de Estudiantes Universitarios Sinaloenses (FEUS) convocó a los sectores populares de la entidad a la lucha armada contra el Estado mexicano.

Fueron cientos de jóvenes cuyos orígenes se encontraron en las diferentes escuelas y facultades de la Universidad Autónoma de Sinaloa (UAS) agrupados en "células clandestinas" insertados y desplegando trabajo político con claros propósitos insurreccionales entre invasores de predios urbanos, choferes del transporte público, obreros de la construcción, jornaleros agrícolas y los espacios propios de la institución educativa a la que pertenecían.

Conformados por pequeños contingentes integrados por alumnos de preparatoria o profesional, habitantes de las casas del estudiante universitario "Rafael Buelna Tenorio", "Genaro Vázquez" o Unidad Habitacional de la Escuela Superior de Agricultura o los diferentes Comités de Lucha pertenecientes a la unidad académica de procedencia. En su inmensa mayoría sus miembros eran de extracción social humilde, de ahí sus simpatías por buscar la transformación radical de la sociedad.

Las zonas de mayor activismo político donde operó la "Enfermedad", serían los valles circundantes y la propia capital del estado: Culiacán. Ello tiene su explicación. El desarrollo de una agricultura capitalista asentada en el valle circundante a ésta generó la migración de miles de jornaleros agrícolas provenientes del sur del país con resultados funestos para su vida. La miseria y explotación laboral serían la tónica dominante. Este fenómeno social contribuiría más tarde como condición legitimadora de aquellos que a través de la violencia simbólica y física buscaban cambiar esta situación. Por otro lado, la mayoría de las instalaciones universitarias y por ende la matrícula estudiantil y magisterial se 
ubicaban en dicha zona del estado con lo cual la presencia universitaria se convertía en una constante.

En su haber, encontramos convocatorias a paros y huelgas en demanda de mejores condiciones laborales y de existencia, invasiones de predios urbanos y agrícolas, agitación política dentro y fuera de la universidad, un uso "masivo" de la escritura para publicitar a la sociedad local su proyecto "revolucionario", intentos insurreccionales, fueron parte de las múltiples formas en que un grupo estudiantil apeló al uso de la violencia como el instrumento idóneo para conseguir sus objetivos políticos: utilizar la lucha armada e instaurar su concepto de socialismo.

Fueron 6 años de intervenir y apropiarse del espacio público local demandando a través de una diversidad de medios, la concreción de los fines para los que surgió este fenómeno de radicalismo político entre los universitarios sinaloenses que se aglutinaron en torno al lema: Revolución o Muerte. Venceremos. Los resultados de su trajinar no fueron los esperados. Al igual que el destino de la organización político-militar de carácter urbano a la que pertenecieron -la Liga Comunista 23 de Septiembre, fundada en la primavera de 1973 en la ciudad de Guadalajara, Jalisco e integrada en su inmensa mayoría por estudiantes radicales de otras universidades del país al igual que ellos-el fracaso, las detenciones, muertos y desapariciones forzadas de militantes, fueron su trágico destino.

Este trabajo no pretende abordar cuáles fueron los factores de orden estructural que detonaron la aparición de la "Enfermedad" como reiterativamente cierta historiografía antigua y reciente se empeña en seguir continuando ${ }^{3}$ donde la revolución cubana, la crisis de la izquierda mexicana, el autoritarismo estatal y la crisis del desarrollo estabilizador, detonan su emergencia, tampoco abrir una discusión en unas cuantas líneas sobre las teorías que explican la violencia y cuál podría ser la que se ajuste más a nuestro objeto de estudio. No es así. Nuestros objetivos son otros.

Si bien para entender este fenómeno de violencia política que en cierta medida fue una constante en el México de la década de los 70's del siglo XX es

\footnotetext{
${ }^{3}$ LÓPEZ DÍAZ, Jaime. Diez años de guerrilla en México, HUACUJA, Mario y WOLDENBERG, José. Estado y lucha política en el México actual, HIRALES MORÁN, Gustavo. La Liga Comunista 23 de Septiembre. Orígenes y naufragio, GUEVARA NIEBLA, Gilberto. La democracia en la calle, ALONSO VARGAS, Jorge Luis, Los guerrilleros mexicalenses, CARRASCO GUTIÉRREZ, Leticia, La guerrilla en México, 1970-1976. el caso de Guadalajara: la Liga Comunista 23 de Septiembre, GARCÍA. Carlos, Destello de una explosión, LÓPEZ LIMÓN, Alberto. Historia de las organizaciones político-militares de izquierda en México, RENTERÍA, Carlos. Guerrero en primera plana, SÁNCHEZ PARRA, Sergio Arturo. La guerrilla y la lucha social en Sinaloa: 1972-1974, por citar algunos trabajos.
} 
necesario tener un marco histórico de referencia que ubique al fenómeno en su contexto o bien del universo de aportes teóricos en torno al estudio de la violencia alguna de ellas puede darnos luz, el propósito de esta escritura de la historia es indagar la forma y lugares en que un segmento de la organización estudiantil sinaloense (FEUS) aprendió una cultura política radical: por eso las preguntas ejes son: ¿qué características asumió el proceso de educación política radical de dichos estudiantes?, ¿cuáles fueron los espacios de sociabilidad donde se fermentó esa cultura política proclive al uso de la violencia?, ¿qué se hacía en esos espacios para educar políticamente a los estudiantes?.

\section{Las características del proceso}

Explicar su aparición y desarrollo tiene como condición necesaria e indispensable abordar los fenómenos de carácter político, como se desarrollaba al momento la relación Sociedad Civil-Estado en donde la primera, en reiteradas ocasiones había sido víctima de la represión y autoritarismo oficial, los procesos que operaron al interior de partidos sobre todos los declarados como de izquierda, el PCM en particular, así como al interior de los diversos movimientos estudiantiles que habían surgido en diferentes regiones del país.

Por otro lado, resulta indispensable ponderar el modelo económico denominado como "Desarrollo Estabilizador" (1954-1970) que el Estado Mexicano desplegó durante más de una década, cuyas repercusiones se hicieron sentir en el país como en la entidad sinaloense. Como saldo negativo de este modelo, las desigualdades sociales se agravaron y tras las señales de agotamiento trajo como respuesta la emergencia de un sinnúmero de movimientos sociales en el campo y ciudades mexicanas.

No podemos olvidar como parte integrante del conjunto de factores estructurales que posibilitaron la aparición de expresiones políticas radicales, armadas en el país la adopción en el imaginario sociopolítico de ciertos grupos de izquierda de un universo de discursos ideológicos (guevarismo, foquismo, revolución cubana o cultural china) que estimularon y guiaron los métodos y estrategias que utilizaron una diversidad de siglas con las cuales se identificaron diversas organizaciones clandestinas que aparecieron en el México de los 70's del siglo XX.

En nuestro caso, la aparición de los "Enfermos", fue un proceso lento pero irreversible de radicalización política al interior de la organización estudiantil sumándose a los factores anteriormente mencionados, es insoslayable valorar las condiciones propias que asumieron el movimiento estudiantil y su dirigencia 
FEUS en ese entonces. La lucha desplegada durante la etapa denominada de "Reforma Universitaria" contra el rector, impuesto por el Ejecutivo del estado a través de la Junta de Gobierno, Gonzalo Armienta Calderón (1970-1972), detonó una vez más la movilización estudiantil.

Durante 2 años, la comunidad universitaria se volcó en su inmensa mayoría a la lucha contra una autoridad considerada como "títere" del poder ejecutivo local. Paros, huelgas y tomas del Edificio Central, espacio fundamental en la historia de la UAS, fueron parte de las acciones instrumentadas por aquellos antagonistas del armientismo. Del otro lado, ceses de profesores, expulsiones de alumnos, clausura de las casas del estudiante universitario y un ingrediente más, la intervención de los “efectivos del orden” (policías, judiciales y militares) que contribuyeron a mantener en el cargo a un rector.

Éste último ingrediente tuvo funestas consecuencias. El 7 de abril, en otra de tantas intervenciones en el perímetro del Edificio Central, las balas disparadas contra estudiantes segaron la vida de dos de ellos: Juan de Dios Quiñónez y María Isabel Landeros. Sus asesinatos provocaron la renuncia al cargo de Armienta Calderón.

Se cerró ahí una fase más de la historia de la vida universitaria caracterizada por una amplia participación estudiantil en los asuntos domésticos de la institución. Llegó un nuevo rector Licenciado Rodolfo Monjaraz Buelna y las demandas de autonomía, democracia participativa se cumplieron.

Parecía que todo volvería a la normalidad. No fue así, repentinamente un discurso y una práctica política comenzó a cobrar fuerza. De las ya tradicionales demandas de independencia del estado, paridad maestro-alumno en los órganos de gobierno universitarios se pasó por parte de un grupo a proponer un nuevo tipo de demandas. En adelante el campo semántico de los estudiantes se modificó abruptamente: revolución, violencia revolucionaria, muerte a la burguesía y su estado, guerrilla, comenzaron a constituirse en el referente obligado de las creaciones lingüísticas de ellos.

Dicho fenómeno comenzó a perfilarse en los albores del año de 1972. A través del periódico estudiantil “Caminemos”, vocero de la confrontación contra el rector impuesto, se difundieron las expresiones que marcaban un nuevo rumbo a seguir, comenzaron a publicitarse;

La alternativa del movimiento estudiantil nuestro (y nacional) es: unirse resueltamente a la lucha que los campesinos están librando por la tierra que les pertenece, a los obreros que se levantan contra 
el charrismo sindical y por la democracia en sus sindicatos. Son ellos -los obreros y los campesinos- los que en definitiva cambiarán el sistema opresivo imperante por una sociedad diferente, los que harán la revolución que librará el país de la explotación, del hambre, de la incultura, al tomar las tierras, las fábricas, es decir, los medios de producción que hoy detentan una minoría. Y en esta lucha, los estudiantes debemos estar siempre con los obreros, siempre con los campesinos. Hay que organizarnos en la universidad para echar a ésta a la calle a manifestarse junto a los explotados. Luchar por consignas de la clase obrera debe ser la consigna, la burguesía advierte ya el peligro de un verdadero movimiento social, porque sabe que los que serán sus sepultureros no están solos, sino acompañados de los estudiantes que comprenden que, en última instancia, será la lucha junto a las clases explotadas las que liberarán a la Universidad y a la sociedad. ${ }^{4}$

Del discurso se pasó a los hechos. En mayo de 1972, la "Enfermedad" se hizo con el control de la dirigencia estudiantil y con ello se impulsó como prioridad la lucha ya no por las transformaciones internas de la UAS o bien, los fines para los que la misma debería servir serían: la revolución y la búsqueda de instaurar la dictadura del proletariado en la entidad y el país.

Tres frentes de "guerra" abrió este grupo para impulsar las tareas que asumió como propias el autodenominado "destacamento de vanguardia del proletariado": la lucha campesina, urbano popular y entre los jornaleros agrícolas.

Convocatorias a mítines, invasiones de tierra y movilizaciones callejeras fueron los medios a través de los cuales se buscó concretar unos objetivos políticos. La lucha desplegada no estuvo exenta de la represión estatal. Intervenciones de los cuerpos policíacos, cercos militares a predios agrícolas invadidos por solicitantes de tierras, detenciones de líderes estudiantiles y populares o muertes de campesinos resultó ser la respuesta que desde el gobierno de Alfredo Valdez Montoya se instrumentaron en contra de los sectores movilizados y dirigidos por la "Enfermedad".

La persecución oficial contra los sectores movilizados se convirtió en "condición normal" en Sinaloa. A la protesta de los sectores que se sentían agraviados por las políticas gubernamentales en el campo, como respuesta sintieron los "excesos" del uso de la fuerza de parte de quienes dirigían los destinos de Sinaloa en ese entonces. La "violencia legítima" al igual que la empleada frente a una movilización estudiantil que impugnaba a un rector espurio tuvo saldos funestos. Periódicamente las notas de los diarios de la entidad darían

\footnotetext{
${ }^{4}$ Caminemos, No.7, abril de 1972, p.1.
} 
puntual referencia de la sangre que corría por los valles agrícolas en donde inermes campesinos eran víctimas de la represión gubernamental escudada en proteger el "estado de derecho".

No obstante ello, quienes convocaban a la confrontación con las autoridades no se atemorizaron con los resultados obtenidos con la intervención gubernamental. Por el contrario, el asesinato de 2 campesinos en el verano de 1972 en un predio ubicado en el municipio de El Fuerte, ubicado en la parte norte de la entidad, contribuyó a exacerbar los discursos radicales proclives a legitimar el uso de la violencia;

Qué significa esta masacre?. Significa que el gobierno perro fiel de la clase capitalista, seguirá apoyando a los capitalistas. El espíritu de Zapata vuelve a estar presente en la acción revolucionaria de los campesinos que más temprano que tarde se cobrarán uno a uno todos los atropellos del gobierno y vengará una a una las muertes de sus hermanos de lucha. ¿Cuál debe ser la actitud de los estudiantes ante esta agresión? Promover la solidaridad efectiva no solo en el medio estudiantil sino en todo el campo sinaloense. Estar ahí, en la lucha junto a ellos, unir su suerte con la de los campesinos y promover la agitación campesina en todo el estado para dar la respuesta que se merecen los asesinos. Ante la violencia organizada del Gobierno, la respuesta debe ser la ¡VIOLENCIA ORGANIZADA POR PARTE DE LOS CAMPESINOS! Ante los “medios legales”, la respuesta debe ser ¡NO CONFIAR EN QUIENES LOS HAN ENGAÑADO POR TAN LARGO TIEMPO!, ;VIVA EL MOVIMIENTO CAMPESINO!, ;VIVA LA UNIDAD CAMPESINOS, OBREROS Y ESTUDIANTES!, ¡TIERRA O MUERTE. VENCEREMOS!. ${ }^{5}$

Esta producción discursiva, de la infinidad que redactaron y distribuyeron entre los sectores populares y universitarios sinaloenses, mostrarían cómo evolucionaba el proceder político de un grupo estudiantil y explicitaba los medios y fines para los que aparecía. Meses más tarde, éstos claramente quedaron definidos, el tránsito a la clandestinidad en que públicamente se declararon en octubre de 1972, su incorporación a una organización político militar como lo fue la Liga Comunista 23 de Septiembre en los primeros meses del año siguiente, la lucha contra el Estado y sus fuerzas de seguridad fueron los resultados de una educación política que reivindicó la movilización y confrontación con el "enemigo de clase".

${ }^{5}$ ARCHIVO GENERAL DE LA NACIÓN (AGN), Sección: 2, Fondo: Dirección de Investigaciones Políticas y Sociales, c.: 1226-A, T.I, pp. 271-273, junio de 1972. 
Sin embargo, cada una de las iniciativas instrumentadas, no importando fecha ni saldos favorables o desfavorables obtenidos, necesariamente tuvieron que planearse, discutirse en algún "espacio autónomo" donde el control estatal estuviera relajado o francamente diluido.

Durante los años en que la "Enfermedad" actuó con mayor o menor fuerza en la entidad a través de la guerrilla urbana a la que decidió incorporarse, los lugares "naturales" de sus ejercicios sociabilitarios, serían fundamentales en ello.

\section{Los espacios de las sociabilidades "enfermas" o donde se fermentó el uso de la violencia}

Intervenir y apropiarse del espacio público por parte de cualquier grupo, no importando los fines para los cuAles se hace uso de él, tiene como condición indispensable el surgimiento de nuevas formas de sociabilidad entre éstos. El concepto de sociabilidad remite a; "la aptitud de vivir en grupos y consolidar los grupos mediante la constitución de asociaciones voluntarias". 6

Su constitución supone la interiorización de ciertos códigos y reglas de conducta que predisponen a un intercambio de ideas y opiniones de manera común entre un conjunto de individuos en una época histórica determinada. De ese intercambio relacional surge una cosmovisión que se comparte por todos los miembros que bien puede expresarse de manera discursiva o a través de la participación directa, personal de los mismos promoviendo o detonando el cambio social.

Todo grupo organizado, que posee estructura dirigente y la compone una militancia más o menos homogénea, que los identifican de los demás, despliegan formas de sociabilidad que implican necesariamente funciones políticas de acuerdo con los planteamientos de Jordi Canal. ${ }^{7}$ Estas características que asumen los mismos desembocan necesariamente en la intervención en el espacio público empleando un sinnúmero de recursos para tal efecto.

Las funciones se caracterizan por la instrucción y formación política de su militancia, práctica educativa que de manera permanente realizarían en este caso "Los Enfermos" tanto en las Casas del Estudiante como los distintos Comités de Lucha que conformaron.

${ }^{6}$ AGULHOM, Maurice. (2004): Historias Vagabundas, México, Instituto Mora, p.54.

${ }^{7}$ CANAL, Jordi. (2006): Banderas blancas, boinas rojas. Una historia política del Carlismo, 1876-1939, Madrid, Marcial Pons, 2006, pp.103-108. 
Por otro lado, el tipo de relaciones desplegadas entre sus miembros, el intercambio de ideas, consensuarlas traería profundas repercusiones en la vida del grupo de orden simbólico. Las discusiones, prácticas de lectura a establecer contribuyeron a la elaboración de un conjunto de representaciones sociales, donde, predominarían dos de ellas. En primer lugar, la creación de una sociedad utópica, igualitaria, una comunidad ideal y en segundo término, la vía por la cual podrían materializarse dicho proyecto. En un poema intitulado "Oda al Che", escrito por algún militante del Comité de Lucha de la Preparatoria Central pueden encontrarse el universo de deseos y aspiraciones que simbólicamente se reproducían en lo más íntimo de los ejercicios relacionales y más tarde expresados a través del espacio público. En él se señalaba;

En una clase en la Universidad al entablar una discusión un compañero me preguntó

Ernesto Che Guevara ¿Por qué murió?

el Che Guevara murió por ti por los pueblos oprimidos del mundo murió contra la injusticia y por la libertad.

Con grandes ojos me miró y asombrado me preguntó por qué matarlo si él luchó contra la injusticia y por la libertad.

Dije, eso es parte de un sistema infeliz pero pronto eso llegará a su fin las masas oprimidas se levantarán y luego el socialismo implantarán.

El Che Guevara por ti luchó

el Che Guevara por ti luchó por los pueblos oprimidos del mundo murió contra la injusticia y por la libertad.

La vida siempre ha sido así contra la injusticia y por la libertad formaremos una nueva sociedad y por ello haremos la Revolución. ${ }^{8}$

${ }^{8}$ El Diario de Culiacán, 11 de junio de 1973, p.9. 
Acorde con esas ideas, explicar cómo fue posible que un grupo estudiantil apelara al uso de la violencia como el instrumento idóneo para impulsar y materializar sus propósitos pretendidamente revolucionarios, es necesario conocer sobre los espacios en los cuales a través de múltiples ejercicios sociabilitarios, llegaron a la conclusión que sólo utilizando la violencia física o discursiva podían materializarlos.

De entre el universo de lugares donde la comunidad universitaria local, no importando su signo político utilizó como el ambiente idóneo para intercambiar opiniones, generar consensos y traducirlo en una conducta política al seno de la "Enfermedad", predominaron dos: las casas del estudiante "Rafael Buelna Tenorio", "Genaro Vázquez" la Unidad Habitacional de la Escuela Superior de Agricultura y los comités de lucha de cada una de las escuelas y facultades de la UAS. En estos espacios fue donde esa cultura política radical proclive a usar y legitimar la vía armada se fermentó, de acuerdo con Barrington Moore;

Para que se ponga en marcha cualquier transformación social, parece haber un prerrequisito que subyace a todos los hasta ahora descritos: el espacio social y cultural (alterna) dentro del orden prevaleciente. Una sociedad con espacios de este tipo proporciona enclaves más o menos protegidos dentro de los cuales los grupos oprimidos o insatisfechos encuentran un lugar en donde desarrollar sus acuerdos sociales distintivos, sus tradiciones culturales y las explicaciones del mundo que los rodea. ${ }^{9}$

Ello más tarde se tradujo en una adopción de un comportamiento individual y colectivo que hizo de la violencia física y simbólica el eje de la forma en cómo intervendrían-apropiarían del espacio público local.

\section{Los Comités de Lucha}

Sus orígenes se remontan a las estructuras organizativas creadas por el movimiento estudiantil de 1968 en la ciudad de México, como las brigadas y el propio Consejo Nacional de Huelga $(\mathrm{CNH}) \cdot{ }^{10}$ La característica de un Comité de Lucha era; "ser un organismo de coordinación en cada escuela y responsable

${ }^{9}$ BARRINGTON, Moore Jr. (1998): La injusticia social: bases de la obediencia y la rebelión, México, Ed. UNAM, 1998, p.455.

${ }^{10}$ En el terreno organizativo, el 68 ofreció la oportunidad al movimiento estudiantil de organizarse por vías y métodos que garantizaran primero: la participación militante de las bases, por medio de la actividad desplegada a través de las brigadas de agitación y propaganda; y segundo: la creación de organismos representativos altamente democráticos a nivel de escuela, los comités de lucha, a nivel de participación global, el consejo nacional de lucha, El Manifiesto, noviembre de 1973, No.8, p.3. 
de organizar comisiones y brigadas en cada centro escolar, esta forma de organización no era nueva ya que había sido usada en anteriores luchas (médicos, los cívicos en Guerrero, los ferrocarrileros, etc.). ${ }^{11}$

Existieron en cada una de las escuelas y facultades de la UAS a la vez que en el Instituto Tecnológico de Culiacán, del cual, algunos de sus integrantes decidieron incorporarse a la clandestinidad armada. Fueron los semilleros al igual que las Casas del Estudiante, de la cual cabe destacar, muchos eran moradores, los principales cuadros activistas y dirigentes del "Enfermismo" y posteriormente, la Liga Comunista 23 de Septiembre en Sinaloa.

Su estructura orgánica era horizontal, donde los comisionados o responsables de Prensa y Propaganda, Finanzas, debían contribuir a que las brigadas estudiantiles que de ellos emanaban, rápidamente se vincularan con la lucha universitaria y popular. ${ }^{12}$

Lugares de reunión de activistas y dirigentes estudiantiles donde circulaba todo tipo de literatura "radical", de debate e intercambio de ideas y construcción de un consenso en torno a una iniciativa común que bien podía expresarse en movilizaciones junto a los sectores populares como de manera simbólica expresar deseos y aspiraciones de transformación social que sólo con el uso de la violencia podían obtenerse; Del discurso a los hechos. Los integrantes de los distintos Comités, integrados a la Liga Comunista 23 de Septiembre a partir de la primavera de 1973 debido a las decisiones tomadas por sus dirigentes, literalmente sin consultarlos, participarían en las distintas acciones políticas y militares que esta organización implementó en la entidad.

Entre las que destacarían, se encontró el de la Preparatoria Central, quienes sobresalieron no sólo por las labores de agitación y propaganda en Culiacán y sus valles circunvecinos durante la realización de las "Jornadas Revolucionarias de Agitación y Combate para destruir al Estado Burgués”, sino también por su capacidad de elaborar una abundante producción textual donde reproducían valores, imaginarios de contenido político radical o donde llamaban a la movilización o sobre las repercusiones que ésta podría traer entre los estudiantes;

$1^{\circ}$. Que es necesario y primordial para el movimiento estudiantil el saber diversificar nuestras formas de lucha, esto es, no caer en la unilateralidad, en la repetición, porque el enemigo

\footnotetext{
${ }^{11}$ REYES PELÁEZ, Juan Fernando. "Un largo camino para el asalto al cielo: notas acerca del Movimiento Revolucionario en: Sinaloa”, en Para romper el silencio. Expediente Abierto, México, CIHMA A.C., nov. 1994-ene. 1995, no. 2, p.7.

12 SANTOS CENOBIO, Rafael. (2007): Los Enfermos: un movimiento político armado en Sinaloa: 1972-1976, Guadalajara, Tesis de Maestría en Historia de México, Universidad de Guadalajara, 2007, pp. 148.
} 
también aprende y pronto está en la capacidad de golpearnos si no desarrollamos nuevas y variadas formas de ataque contra el capital y sus representantes, si no ubicamos nuevos objetivos para nuestra ofensiva y si no sabemos recurrir a la defensa apropiada, para en todo momento mantener el principio fundamental de nuestra guerra contra el capital: conservar y acrecentar nuestras fuerzas y aniquilar las del enemigo. $2^{\circ}$. Que en ésta fase del movimiento en su conjunto debe preparar las condiciones para poder seguir desarrollando la lucha revolucionaria aún en las peores condiciones de represión, condiciones políticas y materiales sin las cuales vamos a vernos nuevamente no en una situación defensiva, sino ante una derrota que la liquide al grueso de nuestras fuerzas o impida el desarrollo ascendente de la lucha proletaria en el estado y en el país. ${ }^{13}$

Un primer momento y espacio para el cultivo y práctica de las sociabilidades serían estas formas organizativas entre los universitarios sinaloenses. El otro, determinante en la configuración y radicalidad "Enferma", serían las "Casas del Estudiante" "Octubre Rojo" en Mazatlán, "Genaro Vázquez" y sobre todo, la "Rafael Buelna Tenorio", ambas ubicadas en la capital del estado. De las casas, cuyo origen se encontró en el movimiento de reforma universitaria, saldrían no sólo los activistas y guerrilleros, sino cuadros dirigentes de la dirección nacional de la LC23S como Eleázar Salinas Olea y Jorge Luna Lujano. ${ }^{14}$

\section{Las casas del Estudiante: “Genaro Vázquez”, "Rafael Buelna Tenorio y Unidad Habitacional de la E.S.A."}

Según James Scott, una rebelión o quienes están dispuestos a llevarla a cabo, necesitan de espacios autónomos, sin vigilancia o control de los grupos dominantes. Dada su naturaleza, se convierten en espacios donde se teje un discurso oculto de la resistencia de los grupos en condición de subalternidad. ${ }^{15}$ Es en estos "espacios sociales" donde los sujetos libremente formulan opiniones de todo tipo, donde ya no es necesario callarse frente a los demás o quienes detentan el poder. En ese ambiente sin "ataduras" emerge desinhibido el discurso oculto pues los lugares donde se produce y quienes lo producen comparten un mismo punto de vista.

${ }^{13}$ ARCHIVO HISTÓRICO DE LA UNIVERSIDAD AUTÓNOMA DE SINALOA (A.H.UAS), Fondo: César Cristerna, s/f, presumiblemente redactado en el verano de 1972 .

${ }^{14}$ LAGUNA BERBER, Mauricio Abraham, La Liga Comunista 23 de Septiembre, Inédito, p. 5. 
Al seno del grupo "Enfermo" tres lugares, ad hoc para sus prácticas relacionales, cumplieron con dichas funciones: los Comités de lucha y sobre todo, las Casas del Estudiante Universitario.

\section{La “Genaro Vázquez”}

Sus orígenes se encuentran en la lucha desplegada por FEUS, primeramente en 1968 cuando ésta fundó la casa que lleva por nombre de uno de los Generales más jóvenes de la Revolución Mexicana y símbolo de la rebeldía estudiantil sinaloense. Posteriormente durante la administración impuesta de Gonzalo Armienta Calderón surgió la llamada primeramente "Casa del Estudiante Universitario Benito Juárez". Su fundación tuvo como objetivo neutralizar la influencia que ejercían los moradores de la primera en el movimiento estudiantil en su lucha por expulsar de la UAS al citado rector. ${ }^{16}$ En la confrontación ante la legitimidad y fuerza de FEUS, quienes moraban en la "Benito Juárez", ${ }^{17}$ decidieron gracias a la infiltración y agitación de moradores de la "Rafael Buelna Tenorio" en su interior pasar a formar parte de la oposición activa en contra de Armienta Calderón.

Espacio para la articulación de sociabilidades entre los moradores, la "Genaro Vázquez", al igual que el resto de casas del estudiante se convirtieron en lugares para la discusión y formulación de proyectos políticos por parte de los estudiantes, mismos que se ponían en práctica en las diferentes movilizaciones populares que se desplegaron en la entidad. Informes de agentes de seguridad del Estado indicaban permanentemente de los debates que se escenificaban en su interior;

se ha discutido ampliamente lo anterior acordándose incrementar las actividades tanto en el campo como en la ciudad antes de salir de vacaciones para lograr una verdadera unidad campesina, obrera, estudiantil que permita presentar una lucha más a fondo contra los burgueses que se encuentran en el poder. También acordaron integrar brigadas ente los alumnos de la Universidad, antes de que salgan de vacaciones cosa que harán el día último del presente mes, con el fin de no descuidar el aspecto campesino y estar pendientes de cualquier movilización que se requiera para evitar una represión de los cuerpos policíacos. ${ }^{18}$

${ }^{15}$ SCOTT, James. (2005): Los dominados y el arte de la resistencia. Discursos ocultos, México, ERA,pp.149-154.

${ }^{16}$ SANTOS CENOBIO, Rafael, Op.cit.

${ }^{17}$ Habitaban este espacio universitario 70 estudiantes distribuidos en el conjunto de escuelas y facultades de la UAS en ese periodo, sus dirigentes fundadores fueron GONZÁLEZ SÁNCHEZ, Guillermo, Presidente y SÁNCHEZ, Guillermo, Secretario, dicha información se encuentra en el AHUAS, Fondo Consejo Universitario.

${ }^{18}$ AGN, Galería: 2, Fondo: DIPS, Caja: 1226-A, T. 1, pp. 213-214, julio de 1972. 


\section{La "Rafael Buelna Tenorio"}

A lo largo del siglo XX el edificio que fue asiento de sus instalaciones fue conocido en Culiacán como "El Mesón de San Carlos", con un pasado que lo señala como el único hotel de la ciudad, escuela sede del Colegio Civil Rosales, ubicado en la parte nororiental de la ciudad entre las calles de Libertad esquina Jesús G. Andrade. A fines de los 60's de esa centuria pasó a ser albergue de cientos de estudiantes provenientes de las regiones que conformaban Sinaloa y el país.

Desde sus primeros años de existencia mostró un floreciente activismo político de parte de sus huéspedes. Informes de las agencias de inteligencia y seguridad del Estado indicaban al respecto;

desde 1969, 12 de sus 190 habitantes realizaron huelgas de hambre, distribuyeron propaganda por la liberación de presos políticos de la cárcel preventiva de la ciudad de México, además de recabar y luchar por obtener mayores subsidios para alimentación y educación. ${ }^{19}$

Para la década de los 70's la morada estudiantil cobró importancia al seno de la lucha que desplegaba la FEUS contra la administración central encabezada por el Licenciado Armienta Calderón. De sus entrañas emergerían cuadros políticos que a través de las Sociedades de Alumnos impulsaron la movilización, el paro de actividades en el Edificio Central y la final expulsión del rector de la UAS.

Con una vida interna caracterizada por uno de sus moradores como "una gran familia", donde la solidaridad, camaradería era la tónica entre ellos, "existía una reglamentación estricta que todos respetábamos, los días del aseo, búsqueda de alimentos en el mercado Garmendia, la participación en las asambleas, discusión de libros en éstas o de manera privada en los cuartos que la integraban, en la lucha popular". ${ }^{20}$

No sólo era un lugar para establecer dinámicas relacionales o practicar la deliberación política. Esta casa del estudiante fue un espacio para la circulación de todo tipo de literatura de corte socialista, "se distribuían revistas de la URSS, China e incluso, teníamos suscripción con editoriales cubanas". ${ }^{21}$

\footnotetext{
${ }^{19}$ Informe Especial sobre la Guerra Sucia en México, 26 de febrero de 2006.

${ }^{20}$ Entrevista realizada a MARTÍNEZ BARRERA, Alonso, Culiacán, Sinaloa, 30 de agosto de 2006.

${ }^{21}$ Entrevista realizada a MARTÍNEZ BARRERA, Alonso, Culiacán, Sinaloa, 30 de agosto de 2006.
} 
Libre, sin cortapisas la Rafael Buelna Tenorio como las demás moradas estudiantiles los libros con contenidos "radicales", "revolucionario" se leían y se discutían en asambleas públicamente o en la intimidad de las habitaciones de manera privada por aquel militante convencido en la necesidad de educarse políticamente para la lucha por venir. Dicha literatura contribuyó a reforzar los imaginarios y valores que motivaron y movilizaron a estudiantes a buscar la revolución proletaria a través de las armas. De acuerdo con Roger Chartier;

Algunos textos permiten la actividad crítica de una manera más aguda que otros, para nosotros, estos textos son los que constituyen un denso patrimonio de referencias literarias y culturales que ayuda a pensar, que permite al individuo situarse en relación con los otros, con el mundo, con la naturaleza, con la trascendencia, y que es el soporte de la actividad crítica. ${ }^{22}$

No sólo cobró importancia en tanto de sus instalaciones circuló o se distribuyó todo tipo de literatura de "izquierda" o que de ella hayan surgido numerosos contingentes que nutrieron la gesta estudiantil. La "Rafael Buelna Tenorio", fue foco trasmisor de todo tipo de reflexiones hechas por estudiantes, dirigentes políticos y guerrilleros, nacionales o extranjeros. Ello fue posible dado que en sus instalaciones se ubicaron las prensas de Caminemos, vocero del movimiento, el cual apareció en el espacio público local a principios de los años 70’s.

Este medio informativo tuvo su propia historia. Dos momentos plenamente diferenciados pueden encontrarse en su línea editorial. Un primer momento, fue "vehículo" difusor entre los universitarios y población culiacanense del punto de vista de los sectores que en un momento reivindicaron la lucha por la Reforma Universitaria, la Autonomía y Gobierno en la UAS, y más tarde del segmento que abrazó primeramente de manera discursiva y posteriormente en los hechos el radicalismo armado.

Con este mas media ahí editado, bien podía debatirse la situación de la denominada "izquierda reformista", la coyuntura política y económica del país e internacional, Caminemos tenía como línea directriz en ser espacio para difundir toda aquella idea o iniciativa que hiciera apología de la violencia revolucionaria. De manera explícita los impresores de él así lo sostenían,

Desde sus inicios CAMINEMOS se propuso ser un periódico revolucionario que, como dice el jefe Lenin, informe, propague las ideas revolucionarias y sea un agitador colectivo. $Y$ en buena medida lo ha logrado. En una sociedad como la nuestra, conciente o inconcientemente todo ser humano al actuar favorece

${ }^{22}$ CHARTIER, Roger. (2000): Cultura escrita, literatura e historia, México, FCE, p. 178. 
a los ricos o a los pobres. Inclusive, el indiferente toma de hecho partido con los explotadores. Éste, nuestro modesto órgano de difusión tomó partido por los explotados, rechazando categóricamente esas ondas de que "somos tribuna para todos los que quieran escribir". ¡Ni madres, reaccionarios!. Aquí no damos libertad para escribir a los apologistas del régimen, a los que sostienen opiniones en contra del movimiento revolucionario. No, señores burgueses jaquí no tienen cabida ustedes!. ¡Aquí tienen cabida sólo quienes expresen los intereses del pueblo, los intereses del movimiento revolucionario nada más!. ${ }^{23}$

Moradas de universitarios y comités de lucha ubicados en el primer cuadro de la ciudad y despliegue de sociabilidades enmarcadas en contextos urbanos. Pero, no sólo en dichos espacios el citado grupo y sus adherentes llevaron a la práctica las mismas. El otro lugar de las dinámicas relacionales, se ubicaría en pleno valle agrícola de la capital sinaloense. Su asiento sería la Escuela Superior de Agricultura (ESA).

\section{La Unidad Habitacional de la ESA}

Frente a las casas del estudiante universitario y comités de lucha de las diversas escuelas que integraron la UAS, todos ellos asentados en el perímetro del Edificio Central o cercano a éste, rodeados de campos agrícolas e instalaciones propiedad de la burguesía agraria estatal, se ubicó el otro espacio por excelencia para el intercambio relacional, la discusión colectiva, creación de representaciones plasmadas en textualidades de diferente manufactura, lugar para la práctica de la agitación política dentro y fuera de sus muros, conocida con el nombre de (UH), se asentó la Unidad Habitacional de la ESA.

Fue creada tras el traslado de las instalaciones de la citada escuela que en un primer momento se localizó en el interior del propio Edificio, durante la administración de Gonzalo Armienta Calderón. Se conformó primeramente por antiguos moradores de las "Rafael Buelna Tenorio" y "Genaro Vázquez", llegando a albergar alrededor de 200 estudiantes en un momento dado. ${ }^{24}$

Por su localización, enclavada en pleno valle agrícola de la capital sinaloense, la geografía jugó un rol fundamental para la discusión, redacción de documentos y las sociabilidades mismas. Ante un ambiente relajado, donde la vigilancia y control de las autoridades universitarias o estatales se diluía, la Unidad, se convirtió junto con el propio Comité de Lucha de la ESA en el espacio propicio para que sus integrantes desarrollaran una importante labor de educación y agitación política "Enferma" y de la propia LC23S.

${ }^{23}$ Caminemos, no. 8, julio de 1972, p. 2.

${ }^{24}$ SANTOS CENOBIO, Rafael. Op.cit. p. 164. 
Convocatoria para efectuar asambleas generales, reuniones del citado Comité. Contribuyeron con su función deliberativa y pedagógica a politizar los espíritus de quienes conformaron dicha comunidad académica. De la mano de algunos de sus principales dirigentes, Carlos Karam Quiñónez (a) "El Balam" y Melchor Bohórquez Landa (a) "El Chino Wuang-Lung", sus moradores, de acuerdo a declaraciones vertidas a las autoridades judiciales por parte de activistas detenidos como Francisco Gamboa, de manera permanente recibieron;

... adoctrinamiento en las teorías socialistas que ha sido a través de las lecturas de varias obras como son El Manifiesto Comunista, El Salario, Precio y Ganancia, El Estado y la Revolución, El Trabajo, es decir El Trabajo Asalariado y El Capital, de Carlos Marx, un documento sobre la tesis de Universidad Fábrica, El Diario del Ché Guevara, así como también se adoctrina en pláticas sostenidas con "El Balam" y "El Chino Wuang-Lung" y con los demás miembros del Comité de Lucha. ${ }^{25}$

Este escenario fue propicio para la articulación de nuevas dinámicas relacionales y creación de espacios para su práctica ejercidas entre los estudiantes universitarios sinaloenses a principios de los 70's. A la par y como resultado de ello, los propios acontecimientos políticos ideológicos que se desplegaban a nivel internacional revolución cubana, cultura china o los diversos movimientos político militares desplegados en Latinoamérica aunado a ello, las movilizaciones sociales en la entidad y la respuesta que el Estado dio a las demandas y exigencias de amplios sectores de la población local, caracterizadas por la persecución, encarcelamiento o el burdo asesinato de activistas y dirigentes populares y estudiantiles generaron una profunda mutación cultural en los referentes mentales de éstos.

El cúmulo de insatisfacciones y reclamos a las autoridades fueron expresados de manera discursiva o diversas textualidades. En ellos, dieron a conocer el punto de vista de quienes decidieron en función de sus elaboraciones políticas, abandonar el discurso de Reforma Universitaria y abanderar uno radical, pretendidamente revolucionario, el cual sería ventilado en el espacio público local.

Las lecturas, discusiones grupales tuvieron su efecto. Sus distintos activistas ya integrados a la organización clandestina, en diversos momentos desarrollaron múltiples iniciativas que se difundieron en ese lugar donde "las personas hacemos uso público de nuestros razonamientos privados" demandando la transformación radical de la sociedad.

El 16 de enero de 1974, fecha en que la Liga llevó a cabo las denominadas "Jornadas Revolucionarias de Agitación y Combate para desgastar al Estado Burgués", la UH y Comité conjuntamente jugaron un papel directriz en la implementación de las mismas en las zonas rurales que circundaron a la ESA.

${ }^{25}$ AGN, Galería: 2, Fondo: DIPS, Caja: 2674, T.1, enero de 1974, p. 229. 
Sobre la participación de ese día, Francisco Gamboa, reconstruyó en parte los objetivos que se propusieron materializar ese día;

...en las primeras horas del 16 dieciséis, o sea al día siguiente se iban a formar brigadas que salieran a los campos agrícolas a orientar a los trabajadores a fin de que éstos se lanzaran a la huelga y exigieran mayores prestaciones a sus patrones, pero que además los componentes de esas brigadas deberían hacer todo lo posible por politizar y organizar debidamente al campesino para que estuvieran estos dispuestos a sumarse a la lucha estudiantil organizando brigadas que en el momento requerido pudieran organizarse en grupos de guerrilleros para luchar contra los ricos ya que esta era la única forma de quitar el poder a la burguesía para poder implantar la dictadura del proletariado. ${ }^{26}$

No sólo en esos momentos los espacios de sociabilidad “Enferma” jugaron un papel determinante en la educación y práctica de una cultura basada en la adopción de la violencia en cualquiera de sus modalidades. En los años subsiguientes, si bien el impacto de grupo tendió disminuir, en el espacio público local seguiría manteniendo una presencia que periódicamente adoptaría una variedad de formas.

\section{CONCLUSIONES}

Ciertamente, la "Enfermedad" como grupo estudiantil radical, que abrazó de manera discursiva y práctica la violencia como el métodos más adecuado para concretar unos fines políticos tiene sus orígenes en una serie de factores estructurales económicos-políticos e ideológicos, resulta fundamental en su aparición y desarrollo todos y cada uno de los lugares en donde ejercieron sus sociabilidades asociativas o formales.

Desde los Comités de Lucha, las Casas del Estudiante Universitario u otros lugares en donde pudieron desplegar sus dinámicas relacionales, contribuyeron a la educación política de sus miembros bajo la concepción de que la violencia revolucionaria articulada en contra del Estado y sus fuerzas de apoyo eran la estrategia para la toma del poder e instaurar la dictadura del proletariado en Sinaloa y México.

En estos "espacios sociales", libres del control de todo tipo de autoridad universitaria o gubernamental, fue posible la circulación de literatura de contenido radical, la puesta en práctica de ejercicios de lectura individual o grupal o la redacción de un universo multivariado de producciones discursivas a través de las cuales los militantes de la "Enfermedad", abrazaron el camino de las armas, la vida en condición de clandestinidad y durante 6 años utilizando una diversidad de recursos acceder al espacio público político e intentar materializar su utopía socialista.

${ }^{26}$ AGN, Galería: 2, Fondo: DIPS, Caja: 2674, T.1, enero de 1974: ff. 218-247. 


\section{FUENTES}

\section{ARCHIVOS CONSULTADOS}

AGN

Archivo General de la Nación

AHUAS Archivo Histórico de la Universidad Autónoma de Sinaloa

\section{FUENTES TESTIMONIALES}

MARTÍNEZ BARRERA, Alonso. Entrevista realizada en Culiacán, el 30 de agosto de 2006.

\section{SELECCIÓN BIBLIOGRÁFICA}

AGULHOM, Maurice. (2004): Historias vagabundas, México, Instituto Mora. Caminemos, voz del Consejo Estudiantil de FEUS, abril-julio de 1972.

CANAL, Jordi. (2006): Banderas blancas, boinas rojas. Una historia politica del carlismo, 1876-1939, Madrid, Marcial Pons.

CHARTIER, Roger. (2000): Cultura escrita, literatura e historia, México, FCE.

ElDiario de Culiacán, junio de 1973.

El Manifiesto, periódico de estudiantes, obreros y campesinos, noviembre de 1973.

LAGUNA BERBER, Mauricio Abraham, La Liga Comunista 23 de Septiembre, Inédito.

MOORE, Barrington. (1998): La injusticia social: bases de la obediencia y la rebelión, México, UNAM.

Informe Especial sobre la Guerra Sucia en México, página Web de The National Security Archive, www.gwu.edu., febrero 26, 2006.

Revista, Para romper el silencio. Expediente abierto, México, CIHMA, AC, nov. 1994enero 1995.

SANTOS CENOBIO, Rafael. (2007): Los enfermos: un movimiento politico armado en Sinaloa: 1972-1976, Guadalajara, Tesis de Maestría en Historia de México, Universidad de Guadalajara.

SCOTT, James. (2005): Los dominados y el arte de la resistencia. Discursos ocultos, México, ERA.

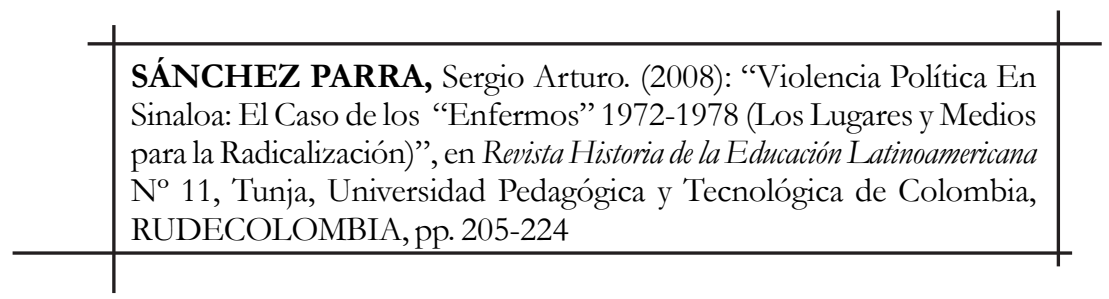

